\title{
An Analysis of the Internal Challenges Faced by Our Army's Military Cultural Confidence
}

\author{
Liu Wenjuan ${ }^{1, \mathrm{a}}$, Wang $\mathrm{Zi}^{1 \mathrm{1}, \mathrm{b}}$, Zhang Mengqi ${ }^{1, \mathrm{c}}$, Fang Hua ${ }^{1, \mathrm{~d}}$ \\ ${ }^{\text {l} C o l l e g e ~ o f ~ I n f o r m a t i o n ~ a n d ~ C o m m u n i c a t i o n, ~ N a t i o n a l ~ U n i v e r s i t y ~ o f ~ D e f e n s e ~ T e c h n o l o g y, ~ X i ~ a n, ~ C h i n a ~}$ \\ afalling2007@163.com \\ b634891907@qq.com \\ c819283781@qq.com \\ d867897654@qq,com
}

\begin{abstract}
Military cultural self-confidence is an important part of cultural self-confidence. It is also a solid spiritual foundation and an important source of strength for our military to achieve the party's goal of strengthening the military in the New Era and build a world-class military. The internal challenges of strengthening the self-confidence of military culture with Chinese characteristics are mainly manifested in the lack of innovation, lack of consciousness, and imperfect construction mechanism of military culture itself. In-depth study of the causes and crux of these internal challenges will help us to further clarify the military. The idea of cultural construction stimulates the vitality and vitality of military cultural self-confidence, and then optimizes the concrete path to strengthen military cultural self-confidence.
\end{abstract}

Keywords: Confidence in military culture, cultural innovation, cultural consciousness, cultural construction

\section{浅析我军军事文化自信面临的内部挑战}

$$
\text { 刘文娟 }{ }^{1, a} \text { 王紫 }{ }^{1, b} \text { 张梦琪 }{ }^{1, c} \text { 方华 }{ }^{1, d}
$$

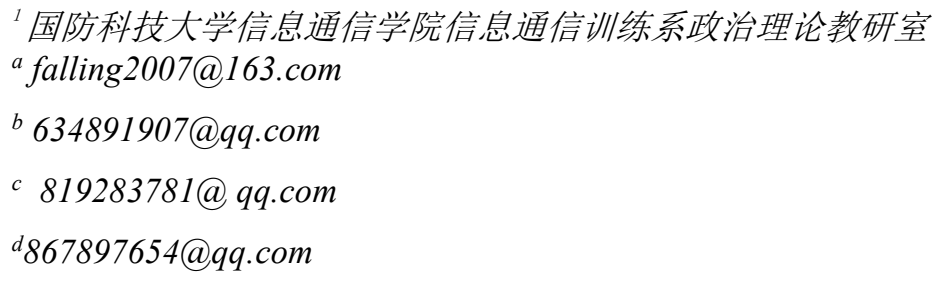

\section{摘要}

军事文化自信是文化自信的重要组成部分, 也是我军实现党在新时代的强军目标、建设世界一流军队的坚实精 神基础和重要力量来源。坚定中国特色军事文化自信的内部挑战主要表现为军事文化自身建设的创新性不足、 自觉性不够、建设机制不健全等, 深入研究这些内部挑战产生的原因和症结, 有助于我们进一步理清军事文化 建设思路，激发军事文化自信的生机和活力，进而优化坚定军事文化自信的具体路径。

关键词: 军事文化自信 文化创新 文化自觉 文化建设

\section{1. 前言}

文化自信是实现中华民族伟大复兴更基础、更深 沉、更持久的精神力量。军事文化自信是文化自信的 重要组成部分, 同时也是我军实现党在新时代的强军 目标、建设世界一流军队的坚实精神基础和重要力量
来源。近年来，伴随中国特色社会主义伟大事业蓬勃 发展, 中国整体的经济实力、科技实力和国际地位等 稳步提升, 中国军队的武器装备、作战能力、国际影 响力等也取得前所未有的进步，中国特色军事文化自 信具备越来坚实的物质基础。但由于长期以来 “重文 轻武” 的民族文化传统、“重经济、轻文化” 的发展观 念、以及整体上“西强东弱”的文化态势等，要建构 
起坚定的中国特色军事文化自信仍面临着许多现实 的挑战。

\section{2. 军事文化创新能力相对不足}

创新是一个国家和民族发展进步的灵魂, 也是军 事文化持续发展、与时俱进的不竭动力。军事领域是 创新技术最集中、竞争最激烈的领域, 军事文化也必 须随着战争方式、作战样式、武器装备等更新而更新。 然而, 由于文化建设观念滞后、技术手段制约等因素 影响, 当前我军军事文化创新能力还存在明显的短板, 与发达国家军事文化水准还存在较大差距。

\section{1. 军事文化内容研究创新能力不足}

首先在军事文化内涵深度上挖掘不够, 存在将军 事文化简单理解为军营文化或军旅文化的现象。军事 文化总体上可分为器物类文化、制度类文化、精神类 文化, 它内在地包含着军事思想文化、军事战略文化、 军事科技文化、军事伦理文化、军事制度文化等, 是 一支军队建设、发展过程中积淀和传承的融价值理念、 思维方式、行为习惯等于一体的精神支撑系统。对军 事文化的理解和认识肤浅化、简单化, 就会导致军事 文化活动丰富而军事文化内涵贾乏, 难以发挥军事文 化对军人必胜的作战心理、坚定的作战意志等的积极 影响, 直接影响军队战斗力生成。

其次, 对我军军事文化的特殊性重视不够, 尚未 凝练出独树一帜、有世界影响力的军事文化特色。军 事文化的产生、发展离不开其所处国家和军队独特的 历史和文化背景, 我军的政治属性、发展历程、宗旨 使命等决定了我军别具一格的军事文化传统, 例如强 调党的绝对领导、严明纪律、奉献精神、战斗意志等, 这与西方军队强调职业精神、法制传统、实用主义等 价值观念存在较大差异。然而, 与西方军事文化强势 宣传和扩张相比, 我军军事文化的品牌化、特色化程 度还远远不够。

再次, 对军事文化与社会文化的共生关系把握不 够, 尚未形成社会文化对军事文化的有力辅助和坚强 支撑。军事文化不是一个仅限于军营内部或军人群体 的封闭文化, 它是社会文化的重要组成部分, 同时又 具有相对独立性。人民军队的性质和宗旨决定了我军 军事文化的先进性和引领性, 要求人民军队在精神文 明建设方面要 “走在社会前列”, 强调军事文化在社 会文化中的模范带头作用, 但社会文化中的错误思想 和不良风气也会影响和反作用于军事文化, 例如拜金 主义、享乐主义、实用主义、利已主义等错误的世界 观人生观价值观, 对先进军事文化存在一定的腐蚀作 用。

\section{2. 军事文化传播手段创新能力不足}

新颖吸睛的传播手段是提升我军军事文化吸引 力和感染力有效途径。一方面, 要着力破解传统传播
方式下受众接受疲劳的问题。以报纸、杂志、广播、 影视、文艺演出等为代表的传统传播方式, 曾经在我 军军事文化建设发展的过程中发挥过重要的积极作 用，但随着信息技术的发展，军事文化传播不能满足 于传统的传播方式，必须搭上 “互联网+” 技术发展 的快车, 大胆使用微博、微信、抖音等新媒体平台, 采用时尚流行、精彩纷呈的新技术传播方式, 积极拓 宽军事文化在国内外的发声渠道, 将中国特色军事文 化的声音和故事在国际国内更好更广泛地传播。另一 方面, 要竭力破除互联网快速传播中的碎片化、标签 化和同质化。军事文化的世界影响力需要长期地浸润 和不断地推陈出新, 而互联网快速传播所带来的副产 品是不可避免地造成传播内容的碎片化、标签化和同 质化, 这与军事文化建设的根本目标背道而驰。因此, 在注重我军军事文化传播范围、传播速度的同时, 要 加强对传播品质、传播机制的监控和管理, 不断增强 传播效益。

\section{3. 军事文化自觉意识比较淡漠}

文化自觉是文化自信的前提和基础, 文化自觉意 识相对淡漠是我军尚未完全确立高度的军事文化自 信的重要原因之一。文化自觉是 “指生活在一定文化 中的人对其文化有 “自知之明”, 明白它的来历, 形成 过程, 所具有的特色和它发展的趋向” ，在 “自知之 明” 的基础上进而实现文化的自我觉醒、自我反思、 自我创新。军事文化自觉, 是指军事文化主体对文化 与军事的内在关系、文化在军事活动中的地位、作用 及其作用方式，文化建设的方针原则以及通过文化建 设促进军事发展的途径和方法等问题的一种理性认 知 。这种理性认知既要求对军事文化整体上的地位 作用、内涵外延等有深刻理解, 也要求对军事文化建 设具体推进过程中的原则、方法、路径等有比较系统 的研究。近年来, 随着党和国家对军事文化工作的不 断重视, 军内外对于推进军事文化建设、坚定军事文 化自信相关工作越来越重视, 但仍然存在部分同志认 识不全面、不深刻的问题。

\section{1. 尚未充分认识军事文化自信对军队改革 发展的重要作用}

部分同志不能运用马克主义立场、观点和方法论 认识和解决问题, 不能树立军事文化是影响和制约军 队改革发展重要因素的正确认识, “唯技术论” “唯武 器装备论” “军事文化无用论” 等错误观点还存在一 定市场, 需进一步认清军事文化自信在改革强军建设 世界一流军队过程中的重要作用及其战略地位, 进而 坚定强军信念和决心。

\section{2. 尚未达到对军事文化建设维度的拓展自 觉}

圊于理论思考的难度和现实工作的局限, 部分同 志仍未跳出以军营文化或军旅文化代替军事文化的 
错误认知, 要么将军事文化单纯地归类为精神性文化 活动, 要么将军事文化与作战训练、军事行动相分离, 不能自觉地将军事文化建设落实到军队建设发展的 方方面面, 不能将丰富多彩的军事实践活动抽象凝练 到军事文化层面。

\section{3. 不能妥善处理军事文化建设的共性与个 性问题}

军事文化自信既要有广博深厚的文化积淀和文 化土壤, 也需要有色彩鲜丽的文化花朵和文化果实。 在推进我军军事文化自信过程中, 还普遍存在着只满 足于按部就班地落实上级指示和文件精神要求的规 定动作, 缺乏大量积极主动、参与创造又充满活力、 独具特色的自选动作, 导致我军军事文化建设存在共 性文化上整体水平不高、个性文化上特色不够鲜明的 现象。

\section{4. 军事文化建设机制不够健全}

军事文化建设是一项复杂的系统工程, 需要各级 党委和政治工作部门高度重视、协调推进, 更需要健 全的制度机制做保障。随着中国特色社会主义事业的 不断发展，文化建设越来越受到党和国家的高度重视。 党的十七届六中全会首次提出建设社会主义文化强 国的总目标。党的十八大以来党中央把文化建设提到 了很重要的地位, 特别是 2016 年 7 月把文化自信和 道路自信、理论自信、制度自信并列为中国特色社会 主义 “四个自信”。党的十九届四中全会指出: “坚 持和完善繁荣发展社会主义先进文化的制度, 巩固全 体人民团结奋斗的共同思想基础” ，使文化制度上 升为社会主义国家制度的重要组成部分。党的十九届 五中全会对文化建设高度重视, 从战略和全局上作了 规划和设计, 明确提出到 2035 年建成文化强国。在 文化强国的国家战略推动下, 中国特色军事文化建设 也得到前所未有的重视, 中央军委先后颁发《关于大 力发展先进军事文化的意见》《军队基层文化建设规 定》《政治工作条例》等法规政策, 初步建立起军事文 化建设的制度机制, 但跟国家文化战略发展的客观需 要, 跟全面建成世界一流军队的实践要求相比还存在 一定差距。

\section{1. 军事文化建设顶层设计不够完善, 具体 发展目标不够清晰}

当今世界正在经历百年未有之大变局, 包括中国 在内的新兴国家的崛起, 使世界战略格局和经济秩序 正发生着冷战结束以来最深刻、最复杂的变化。在国 家力量的博亦过程中, 文化战略的地位和作用愈发重 要, 军事实力抗衡中军事文化的影响力辐射力效果也 愈来愈凸显。然而, 受传统保守主义、和平主义等思 想影响, 我军在军事文化建设方面顶层设计的整体上 主动性、战斗性、创新性还不强, 对国际上军事文化 间现实的和潜在的较量与争锋尚缺乏深层次、系统性
考量和谋略, 尚未制定出路线清晰、层次立体、针对 性强的军事文化建设目标。

\section{2. 军事文化建设协同机制不够完善, 尚未 形成军地协同的军事文化建设合力}

军事文化建设离不开国家文化建设, 军事文化自 信既是文化强国战略的一个重要组成部分, 也是文化 强国的一个重要实践支撑。没有军事文化方面强大的 世界影响力, 国家整体的文化强国战略也得不到彻底 有效地实施。然而, 由于国家和军队负责文化建设的 职能部门缺乏业务上的横向联系和协同配合, 常常是 各自为战、互不干涉, 导致军事文化建设无法与国家 和社会文化建设融为一体、相辅相成, 不能在文化建 设上形成合力, 甚至存在军事文化建设落后于地方文 化建设的滞后现象。应加强国家文化战略统一部署下 的军地、军民在文化建设方面的协同合作，着眼打赢 信息化、智能化条件下的现代战争，做好军事文化战 略的落地实施，有计划、有步骤地持续推进中国特色 军事文化建设，提升军事文化建设的质量和效益。

\section{3. 军事文化建设评估交流机制不够健全， 缺乏高质量国内外军事文化互学互鉴}

军事文化建设的效果如何, 需要有客观、准确的 多维度衡量标准, 既要开展军队内部对军事文化建设 效果的评估, 也要综合全社会对军事文化建设的认可 和评价, 还要借鉴国际上先进的军事文化建设经验, 了解国际社会对中国特色军事文化的认识和看法。建 立和健全开放包容的效果评估体制, 有助于我军军事 文化通过国内外、军内外多种角度认清自身建设水平 和定位，对照发展、查找不足，同时有助于我们从社 会文化、其他国家军事文化中汲取养分, 促进军事文 化建设整体质量得到进一步提升。同时, 军事文化与 社会文化之间的信息交流，各种不同军事文化之间的 相互传播, 能够为军事文化输入新的文化因子, 成为 促进军事文化变革和发展的外在推力。

\section{5. 结论}

综上, 军事文化自信是文化自信的重要组成部分, 也是我军实现党在新时代的强军目标、建设世界一流 军队的坚实精神基础和重要力量来源。坚定中国特色 军事文化自信的内部挑战主要表现为军事文化自身 建设的创新性不足、自觉性不够、建设机制不健全等, 深入研究这些内部挑战产生的原因和症结, 有助于我 们进一步理清军事文化建设思路, 激发军事文化自信 的生机和活力, 进而优化坚定军事文化自信的具体路 径。

\section{项目基金}

本文为国家社科基金一般项目《新时代军队文职 人员职业精神研究》 (20BGL312) 的阶段性成果之一。 


\section{REFERENCES}

[1] Fei Xt.(2009)The Life and Death of Culture[M], Shanghai People's Publishing House, Shanghai. Page185.

[2] Fang Yg,Cheng Jb, CheYli.(2006).Military Cultural Consciousness and China's Advanced Military Cultural Innovation[J]. Military History Research, 02:145-154.

[3] The writing group of this book.(2019).The decision of the Central Committee of the Communist Party of
China on several major issues concerning upholding and improving the socialist system with Chinese characteristics and advancing the modernization of the national governance system and governance capabilities[M]. People's Publishing House, Beijing. Page 22

[4] Qu Qs. (2016) Several issues on cultural selfconfidence. Policy[J]. 11: 8-11

[5] Cao Z g. (2013) The Development Path of Advanced Military Culture with Chinese Characteristics. Journal of Xi'an Political University[J]. 5:44-46 